\title{
JUVENTUDE PESCADORA: QUESTÕES CONCEITUAIS, DE CLASSE E O PROCESSO DE CONSTRUÇÃO DO SER JOVEM ${ }^{1}$
}

\author{
FISHERMEN YOUTH: CONCEPTUAL ISSUES ON CLASSES AND THE \\ FORMATION PROCESS OF THE YOUNG PERSON \\ JUVENTUD PESCADORA: CUESTIONES CONCEPTUALES, DE CLASE Y EL \\ PROCESO DE CONSTRUCCIÓN DEL JOVEN
}

\author{
Adenil Alves Rodrigues* \\ Gilmar Pereira da Silva** \\ Doriedson do Socorro \\ Rodrigues*** \\ Egidio Martins****
}

* Mestre em Educação pela Universidade Federal do Pará (UFPA). Graduado em Letras-Habilitação em Língua Portuguesa pela UFPA. Professor Substituto da Faculdade de Educação (FAED/UFPA/ Campus Cametá). Membro do Grupo de Estudos e Pesquisas sobre Trabalho e Educação (GEPTE/UFPA). Cametá, Pará, Brasil. E-mail: adenil2007ufpaa@yahoo. com.br

**Doutor em Educação pela Universidade Federal do Rio Grande do Norte (UFRN). Docente do Programa de Pós-graduação em Educação (Mestrado e Doutorado) do Instituto de Ciências da Educação da UFPA e do Programa de Pós-graduação em Educação e Cultura (Mestrado) do campus de Cametá. Membro do GEPTE/UFPA. Belém, Pará, Brasil. E-mail: gpsilva@ufpa.br

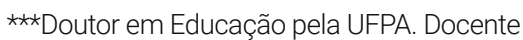
do Programa de Pós-graduação em Educação e Cultura e do Programa de Pós-graduação em Currículo e Gestão da Escola Básica da UFPA. Membro do GEPTE/UFPA. Cametá, Pará, Brasil. E-mail: doriedson@ufpa.br

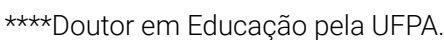
Docente do Campus Universitário do Tocantins (UFPA/Cametá). Membro do GEPTE/UFPA. Cametá, Pará, Brasil. E-mail: egidio@ufpa.br

Recebido para publicação em: 7.8.2018 Aprovado em: 4.6.2019

\section{Resumo}

A partir de um recorte de classe, buscou-se discutir como a juventude está sendo vista por um conjunto de sujeitos que produzem suas existências por meio do trabalho da pesca. Tomando como referência o materialismo histórico-dialético, concluiu-se que os jovens pescadores de Cametá-PA vivem o momento de ser jovem não de maneira plena e socialmente realizável, e sim, truncada, e, não raras vezes, protelada. Contudo, também resistem e lutam contra as negações que são por eles vividas, mostrando, assim, uma clara compreensão da realidade contraditória da qual fazem parte.

Palavras-chave: Juventude pescadora. Classe social. Processo de construção do ser jovem.

\section{Abstract}

From a social division of class cut, this article sought to discuss how youth is being viewed by a group of subjects who produce their existence from the work of fishing. Taking historical-dialectical materialism as a reference, it was concluded that young fishermen from Cametá-PA live the moment of being young not in a full manner and socially achievable, but rather truncated, and often delayed. However, they also resist and fight against the denials they experience, thus showing a clear understanding of the contradictory reality of which they are part.

Keywords: Fishermen youth. Social class. The construction process of the young person. 


\section{Resumen}

A partir de un recorte de clase, este artículo busca discutir cómo un conjunto de sujetos que se ganan la vida a partir del trabajo de la pesca está viendo a la juventud. Tomando como referencia el materialismo histórico-dialéctico, se concluyó que los jóvenes pescadores de Cametá-PA viven el momento de ser jóvenes, no de manera plena y socialmente alcanzable, sino truncada, y a menudo pospuesta. Sin embargo, también se resisten y luchan contra las negaciones que experimentan, mostrando así una clara comprensión de la realidad contradictoria de la que forman parte.

Palabras clave: Juventud pescadora. Clase social. Proceso de construcción del joven.

\section{Introdução}

Se é verdade que nos últimos anos o processo de expansão do capital tem provocado mundialmente grandes transformações em âmbito social, político, econômico e cultural (BOGO, 2010), também não é menos verdade que tais transformações vêm acompanhadas cada vez mais de um reducionismo e obscurantismo no que tange à compreensão dos conceitos de homem e suas fases de desenvolvimento histórico-humano - infância, juventude, idade adulta e velhice.

Um exemplo do que aqui inicialmente se está sinalizando é quando se toma a fase que compreende a juventude, a qual, nesta pesquisa, é tomada não como mera idade de desenvolvimento do homem, mas como construção humana histórico-social, na qual as relações políticas, econômicas, culturais e sociais são bases reais e, portanto, constituem e são constituintes dessa fase da vida (ARAUJO; ALVES, 2013; JUVENTUDE..., 2009).

Geralmente, a definição mais imediata e corriqueira parte do pressuposto de que a entrada na juventude se faz a partir da adolescência, e que a idade é marcada por transformações biológicas, psicológicas e inserção social do indivíduo (DAYREL; GOMES, 1999, p. 3).

O conceito de juventude singular (FRIGOTTO, 2011, p. 99), o qual a caracterizaria apenas como uma população entre 16 e 29 anos de um país ou determinada região, é tido aqui por reducionista, pois a considera apenas como transição para a vida adulta, na qual as transformações de ordem física, biológica e psicológica seriam os pontos centrais que identificariam essa fase da vida. Nesse sentido, a juventude compreenderia apenas aqueles sujeitos que, entre outras características, teriam em comum: a faixa etária, o fato de ainda residirem com os pais, estarem em uma fase escolar que compreende o ensino médio etc.

Por outro lado, contrária a essa compreensão mais comum e imediatista, encontra-se uma outra leitura sobre a definição da categoria juventude: tomada com base em uma perspectiva de classe. De modo que, como construção histórica humana-social, os indivíduos que a compõem, apesar de demarcados por contradições e 
negações de diversas ordens, vão se constituindo como detentores de direitos e deveres diante de uma sociedade cindida em classes (FRIGOTTO, 2011).

Assim, quando vista por uma perspectiva de classe, a juventude aparece não mais como uma singularidade, mas como expressão plural, marcada, principalmente, pelas lutas e contradições de uma materialidade de vida produzida a partir de uma sociedade desigual. Tal coletividade compreende um conjunto de sujeitos que, tendo suas vidas afetadas diretamente pelas condições e contradições de uma sociedade classista, não aceitam o conformismo e a passividade como imposição, o que lhes permite projetar-se para o desafio de lutar por seus interesses, constituindo-se, assim, em "sujeitos de potencial rebeldia e contestação" (JUVENTUDE..., 2009), o que vai permitindo entender esse momento da vida não enquanto transitoriedade, e sim, por um processo em construção.

Busca-se fazer uma discussão da juventude à luz da perspectiva de classe

É entendendo a juventude como processo em construção que o presente texto busca, por meio de um recorte de classe, analisar e compreender o que seja o ser jovem. A partir daí, busca-se problematizar como esse momento de construção humano-social se dá para um conjunto de sujeitos que, atualmente, produzem suas existências graças ao trabalho da pesca.

Para isso, assume-se como base epistemológica o materialismo histórico-dialético (MARX, 2008) e toma-se como sujeitos intervenientes desta pesquisa jovens pertencentes à classe trabalhadora da pesca artesanal no município de Cametá ${ }^{2}$ Nordeste do Estado do Pará, Amazônia, Brasil. Esses jovens produzem suas existências mediados pelo trabalho, com base no intercâmbio que estabelecem cotidianamente com os meios materiais que, no movimento contraditório da realidade, vão lhes constituindo quem são e como se reconhecem.

Buscando fazer uma articulação entre o local e o universal, aqui também utiliza-se um conjunto de dados empíricos, obtidos por meio da aplicação de entrevista semiestruturada (THIOLLENT, 1985) junto a seis jovens ${ }^{3}$ que se mantêm ligados ao trabalho da pesca, sendo esses dados considerados com base na análise de conteúdo 4 (FRANCO, 2007; MINAYO, 2012).

Estruturalmente, o texto está organizado em duas seções: na primeira, busca-se fazer uma discussão da juventude à luz da perspectiva de classe, que no movimento histórico-social, vai permitindo aos sujeitos se constituírem como jovens por meio de um conjunto de relações que são por eles produzidas e vivenciadas.

Simultaneamente às discussões traçadas na primeira seção, a segunda trata especificamente do processo de construção e vivência do ser jovem para um conjunto de sujeitos trabalhadores da pesca. Nessa seção, com base nas entrevistas feitas junto a alguns sujeitos, realizam-se algumas descrições e a análise para compreensão de como os interlocutores da presente pesquisa compreendem e vivem o ser jovem e como esse momento humano histórico-social vai se constituindo a partir de um intercâmbio, do qual participam outros sujeitos jovens, a família, as perspectivas de melhores oportunidades na vida, a comunidade etc. 


\section{Juventude: uma leitura a partir da perspectiva de classe}

Ao elencar a categoria juventude como objeto de estudo, uma primeira questão que se apresentou foi: a partir de que perspectiva teórico-epistemológica está se partindo para se tentar entender essa categoria? Tal questão foi colocada principalmente porque, na perspectiva das correntes teóricas do conhecimento, essa categoria se apresenta sob o viés de duas grandes linhas de construção filosófica: uma metafísica e outra dialética materialista ${ }^{5}$.

Do ponto de vista da concepção metafísica, a juventude se relaciona à ideia de amadurecimento biológico em uma cronologia determinada, uma fase de transição para a vida adulta e de aquisição de experiência (SILVA, 2012, p. 164). Já sob a orientação da concepção dialética materialista, a categoria juventude é apresentada não como abstração, mas como sujeitos sociais concretos, ainda que demarcados pela cisão e fração de classe (FRIGOTTO, 2011, p. 99).

No âmbito da primeira definição (metafísica), a compreensão que se estabelece sobre juventude se sustenta na defesa de que essa fase da vida se apresenta como sendo de certa maneira estável e bem-definida (SILVA, 2012, p. 164), uma estabilidade e uma definição que são garantidos, principalmente, pelas instituições família, escola e trabalho.

Esses jovens

passam a ser

entendidos não

mais enquanto

sujeitos abstratos

e passivos diante

da realidade

Contudo, há de se considerar que essa estabilidade, definitivamente, está em crise. Hoje em dia, conforme aponta Silva (2012, p. 164-165), o que se vê é o surgimento de novas formas de família e uma certa exaustão da ilusão de ascensão social por meio da educação e do pleno emprego, o que faz novos grupos reivindicarem políticas específicas. Além disso, segundo o mesmo autor, o ato de colocar em xeque a cultura do emprego e do salário vem transformando a transição linear, simétrica e ordenada para a vida adulta marcada pela tríade família-escola-trabalho. De modo que esse tripé tem se tornado prolongado, indeterminado e descontínuo, tanto para os jovens quanto para os adultos.

Nesse sentido, tomar a juventude enquanto uma fase fixa e consolidável da vida seria entendê-la como produto de abstrações nas quais o ser jovem é entendido apenas como fenômeno de transição para a vida adulta, o que, por sua vez, não permite se pensar e ver esses sujeitos como construtores de suas próprias histórias e protagonistas de suas relações. Isso porque, quando alcançados nessa segunda forma de olhar, esses jovens passam a ser entendidos não mais enquanto sujeitos abstratos e passivos diante da realidade por eles experimentada, e sim, como sujeitos concretos, históricos, políticos, contestadores da realidade, sujeitos marcados por diferentes transformações físicas e biológicas, mas também, éticas, políticas e sociais (ARAUJO; ALVES, 2013).

É à luz dessa compreensão que este artigo defende que a juventude, longe de ser um tema de fácil conceituação, é, desde o início, um assunto complexo e contro- 
verso. Conforme Frigotto (2004, p. 1), o termo mais correto para referência seria, na verdade, "juventudes", para não se cair em uma perspectiva atomizada, e sim, levar em conta as particularidades que fazem dela um recorte de classe social.

Assim, o que aqui se defende é que a juventude hoje, e mais ainda, a juventude da classe trabalhadora, é composta por sujeitos de construções históricas sociais reais, pois vivem a materialidade prática do cotidiano que em uma relação contraditória Ihes constitui como indivíduos dinâmicos e contestadores da realidade por eles experimentada, desenvolvendo-se, assim, como seres humanizados que não assumem uma única maneira de ser jovem, pelo contrário, apresentam-se enquanto sujeitos constituídos por múltiplas dimensões, as quais, dependendo das situações concretas, são por eles assumidas.

Porém, se por um lado a juventude, em sua concretude, é um fenômeno dinâmico, sendo os jovens sujeitos construtores de suas próprias histórias, por outro, a juventude de forma geral e, mais ainda, a juventude da classe trabalhadora, a despeito dos mandos e desmandos do sistema capital, é dos segmentos que mais têm sofrido as ações perversas e desumanas desse sistema. De acordo com o historiador Eric Hobsbawm (2000), os reflexos dessa perversidade e desumanização expressam-se, principalmente, pela profunda despolitização e alienação pela qual hoje vêm passando os jovens no século 21.

Diante disso, buscar compreender a juventude da classe trabalhadora, e, mais especificamente, a juventude pescadora, à luz das mazelas e descasos produzidos pelo modo de produção capitalista, é condição necessária para se entender esse momento histórico-social da vida humana numa perspectiva não romantizada. Isso porque, se para os jovens de classe burguesa ${ }^{6}$, viver a juventude em sua plenitude está cada vez mais difícil, para os jovens da classe trabalhadora e, mais ainda, para os jovens pertencentes ao grupo social dos pescadores, que constroem suas vidas cotidianamente nas margens dos rios, ou seja, em contextos diferentes dos jovens urbanos, viver a materialidade do ser jovem se torna ainda mais penoso e angustiante.

Silva (2013, p. 81) identificou que os dilemas que as pessoas nessa faixa etária enfrentam, no caso da Amazônia, têm agravantes significativos, como as precárias condições de vida e a falta de escolas que absorva a todos. Conforme um dos entrevistados ${ }^{7}$ da presente pesquisa:

Nós aqui temos que lidar com a falta de muitas coisas. Ser jovem, morador de ilha, não é fácil. Aqui, quase sempre falta tudo e a gente tem que ir 'se virando', improvisando e levando a vida. Ser jovem na Amazônia é isso (F. F. N, 23 anos).

É nesse sentido que os jovens pescadores precisam ser vistos como produtores das interações sociais. Mais que isso, são produtos dessas interações. Dessa forma, suas origens, suas raízes e cultura são resultantes de um processo histórico que, fundamentado em um movimento real e concreto, vem se desenvolvendo e 
mostrando que esses sujeitos, por meio de suas práticas pesqueiras, também são produtores da história. Assim, não podem ser e vistos e entendidos apenas na sua condição de transitoriedade, na qual o jovem seria um "vir a ser", como se tivesse na passagem para a vida adulta o sentido de suas ações no presente.

\section{Juventude pescadora de Cametá-PA: negações, contradições e luta no movimento de construção e vivência do "ser jovem"}

Ser jovem; ter que ajudar no sustento com o trabalho da pesca; morar na ilha, que apesar de ser um lugar muito bom de se viver, tem as suas dificuldades por falta de assistência pública, é penoso e angustiante! (R. C. B, 25 anos)

Tratando-se especificamente dos jovens pertencentes ao grupo social dos pescadores, viver a materialidade da juventude é penoso e angustiante, como relata, na epígrafe anterior, o jovem pescador (R. C. B., 25 anos). Além de estarem imersos em uma realidade tipicamente interiorana, onde o Estado com frequência se abstém de atuar com propriedade (RODRIGUES, 2012b, p. 16), também têm de construir a materialidade de suas vidas a partir da entrada precoce no mundo do trabalho, o que faz com que tenham de encurtar a infância e adiantar a fase adulta. Nesse sentido, significativas são as afirmações que o jovem B.G.J. (24 anos) faz quando coloca que:

Para o jovem que mora no interior, as dificuldades são muito grandes. Para nós, tudo é mais difícil. Nossa lida no trabalho da pesca começa cedo, desde sete, oito anos, porque, na ilha, é assim: cedo, a gente aprende as dificuldades da vida [...]; cedo, a gente aprende que tem que se virar, tem que ser adulto. E a gente percebe que não dá para ficar imaginando como vai ser o amanhã, o futuro; o negócio é ir à luta! É assim que a gente vai vivendo. Não tem como esperar chegar uma idade ' $X$ ' para ir trabalhar. Para nós, começou a aprender a remar, já vai com o pai e com o tio botar malhadeira ${ }^{8}$ para pegar o peixe.

Viver a

materialidade da

juventude é penoso

e angustiante
Partindo da exposição de B.G.J., o que chama a atenção é que os jovens pescadores estão marcados pela negação das condições materiais mínimas necessárias para que possam adquirir os elementos indispensáveis para se desenvolverem. Assim, ficam impedidos de exercerem a plenitude de ser jovens, no sentido de poder fazer suas próprias escolhas, planejar futuro, pois, muito cedo, têm de enfrentar o trabalho da pesca.

Conforme revela o informante, no município de Cametá-PA, os jovens que estão produzindo suas existências às margens dos rios pelo trabalho da pesca estão cindidos por relações de classe estruturalmente desiguais. Frigotto (2011) tem uma explicação para as contradições capital-trabalho que se pode aplicar para 
analisar a fala do informante B.G.J. Para Frigotto, o acesso aos bens vitais ou à reprodução da vida biológica, social, cultural e educacional atinge a juventude em sua dimensão geracional, de tal modo que produz uma existência social truncada ou suspensa.

Também sob a luz de Frigotto (2011), pode-se apensar a fala do jovem F.F.N. (23 anos) quando afirma: "Hoje eu sei que como jovem eu tenho que lutar para conquistar os meus direitos, porque é como dizem, a nossa vitória na vida depende de muita luta". Assevera-se que ignorar que os jovens pescadores são sujeitos que constroem suas próprias histórias significa não levar em consideração que esses jovens pescadores são produtores de interações sociais, mais que isso, são produtos dessas interações.

Em outras palavras, a juventude que aqui se analisa constitui-se de sujeitos que dialeticamente assumem o protagonismo da produção de suas existências, o que os conduz a mudarem, ou seja, a buscarem desenvolver posturas e atitudes que, no movimento histórico-social de luta e defesa de uma vida mais digna, vai lhes transformando e possibilitando viver o ser jovem não apenas enquanto um processo de transição, como outrora aqui nesse texto já se colocou, mas como um movimento de construção humano-social de preparação para o desenvolvimento de uma vida adulta ideologicamente crítica, socialmente madura e politicamente esclarecida. Nesse sentido, profícuas são as colocações que o jovem R.C.B. (25 anos) faz quando indagado sobre a compreensão do conceito de juventude para aqueles que assumem a pesca como trabalho:

Juventude para nós é também um momento que vai nos ajudar a ser no futuro uma pessoa diferente. É na juventude que a gente também aprende alguns valores, algumas ideias sobre a vida, sobre a nossa sociedade, que com certeza vão ser importantes para quando a gente for adulto. Eu até te digo que é na juventude que nós criamos uma compreensão melhor do mundo, mais crítica, que nos ajuda a entender que as coisas não são dadas e que é preciso muita luta, é preciso se unir. Nós pescadores precisamos nos unir porque só assim é que nós vamos conseguir melhorar a vida de todo mundo que pesca. A juventude para mim é isso, é momento de aprendizado para a vida toda.

Tomando o exposto pelos entrevistados, o que aqui também é válido ressaltar é que à luz de uma sociedade cindida em classes, os jovens aqui pesquisados são sujeitos socialmente produzidos, tendo no jogo das relações sociais, que são construídas no contexto de suas vidas prático-cotidianas, suas influências maiores. Dito de outra forma, o conjunto de sujeitos que compõe a juventude pescadora, por serem socialmente construídos, não podem ser considerados apenas como receptores de influências externas, como se em passividade estivessem permanentemente diante de uma realidade contraditória como a capitalista, isso porque os jovens pescadores, aos moldes da lei da dialética, unidade e luta dos contrários (TRIVIÑOS, 1987), 
ao mesmo tempo em que se unificam, pois se veem, agem e vivem como jovens e, no movimento histórico-social, opõem-se, contestando e se rebelando contra as ações do capital, que nega seu modo peculiar pescador amazônida de ser jovem.

Eu vejo assim: o jovem do interior não é só aquele que imita, que reproduz o que o outro faz, por exemplo, imita o estilo do jovem da cidade. Ele não é só aquele que recebe influência de fora. 0 jovem do interior também tem os costumes da comunidade dele, tem a cultura dele, o gosto, tem tudo isso. Mas tem também o outro lado, que é daquele jovem que participa da comunidade ${ }^{9}$, da Colônia ${ }^{10}$, que luta, é atento e está antenado para seus direitos (L.R.C., 22 anos).

Esses sujeitos

\section{também}

buscam a

compreensão

necessária da

transformação

da realidade
Tomando a fala expressa por L.R.C., identifica-se o perfil desses jovens também já definidos por Frigotto (2004, p. 181): filhos de trabalhadores, produzem a vida de forma precária ou por conta própria, no campo e em regiões diversas, com particularidades socioculturais e étnicas.

Os jovens trabalhadores da pesca constroem sua juventude a partir de uma gama de relações que estabelecem ora com seus pares, ora com a natureza, ora com a sua religião, ora com a cultura, enfim, com as mais diversas situações e pessoas de suas relações pessoais e impessoais. Sendo assim, a juventude para os que estão na faixa etária entre 15 e 25 anos e vivem da pesca é momento de construção biológica e histórico-social, provida de ações concretas carregadas de objetividade e subjetividade que, de forma direta e indireta, formam e determinam a vida e a humanização desses sujeitos. Assim, válidas são as colocações feitas E.P.F. (23 anos) quando afirma que

A gente que é jovem tem muita coisa dessa fase da nossa vida que vem do nosso meio, da influência que a gente vive no dia a dia, com a comunidade, que tem o grupo de jovens de que a gente participa, com as próprias pessoas que vivem perto da gente, da nossa família.

Pelo exposto do jovem E.P.F., pode-se afirmar que a fase da vida conhecida como juventude, vivenciada hoje por um conjunto considerável de sujeitos que compõe o grupo social dos pescadores, representa um momento de construção humano-social que, alicerçada em bases concretas, determina nesses sujeitos dimensões éticas, políticas, sociais e culturais, as quais vão Ihes permitindo constituírem-se em uma pluralidade de sujeitos determinados por um modo peculiar de vida, o interiorano. Esses sujeitos também buscam a compreensão necessária da transformação da realidade (KOSIK, 2002). 


\section{Considerações finais}

Ao assumir a constituição do ser jovem a partir de um recorte de classe, busca-se aqui defender a ideia de que para uma parcela significativa dos jovens que se encontram envolvidos com o trabalho da pesca em Cametá-PA, a juventude não está sendo construída baseada em relações sustentadas na passividade, ao contrário, está sendo edificada por um movimento real de luta, contradições e aprendizados estabelecidos cotidianamente por esses sujeitos e o mundo material que os rodeia.

Analisado pela perspectiva histórico-social pautada na busca pelo desenvolvimento de potencialidades, o ser jovem, para além de uma simples fase a ser completada por homens e mulheres em seus desenvolvimentos históricos, é um processo em construção no qual, entre outros, estão envolvidos o desenvolvimento biológico e cultural, mas também, o ético, o político e o social.

Sendo assim, analisar o processo histórico-social de constituição do ser jovem para os sujeitos que atualmente se relacionam com a atividade da pesca significa compreender que, do ponto de vista de suas sociabilidades, estão movidos por suas necessidades e vão estabelecendo relações outras, ora com seus pares, ora com o coletivo de sujeitos que compõem a comunidade na qual participam, em busca de condições objetivas que lhes permitam viver a materialidade do presente na perspectiva de construção de bases reais para o futuro.

\section{Notas}

1 Este artigo é um recorte da dissertação "Juventude, trabalho e educação: a formação da identidade pescadora dos jovens da Colônia de Pescadores Artesanais Z- 16 de Cametá-Pará", sob orientação do Prof. Dr. Gilmar Pereira da Silva (PPGED/UFPA) e Coorientação do Prof. Dr. Doriedson do Socorro Rodrigues (na época da elaboração da pesquisa, vinculado ao PPGED/UFPA e, hoje, atuando no PPGEDUC/PPEB/ UFPA), defendida em 2016 no Programa de Pós-graduação em Educação (PPGED), Universidade Federal do Pará.

2 O município de Cametá, segundo o Instituto Brasileiro de Geografia e Estatística (IBGE, 2008), pertence à mesorregião do nordeste paraense e à microrregião Cametá, apresentando uma área correspondente a $3.122 \mathrm{~km}^{2}$. Ainda segundo o IBGE (2008), o município apresenta uma população de 120.896 habitantes, dos quais 52.838 encontram-se na zona urbana e 68.058 na zona rural. Trata-se de um município com contingente rural maior do que o urbano (RODRIGUES; SILVA, 2014, p. 1).

${ }^{3}$ Os entrevistados foram selecionados com base em três critérios: a idade entre 15 e 25 anos, que é a idade, segundo o IBGE, em que se encontram aqueles sujeitos que são considerados jovens; a ligação com o mundo do trabalho por meio do exercício da pesca; e, por fim, a atuação desses sujeitos em movimentos sociais, tais como: comunidades cristãs, sindicatos, colônia de pescadores etc. 
${ }^{4}$ A presente pesquisa considerou a análise de conteúdo na perspectiva de Franco (2007), por contar com o tratamento e análise de entrevistas e relatos orais dos entrevistados. Considerou-se, também, Minayo (2012), porque preconiza um tratamento diferenciado para a organização e sistematização dos dados, orientando que esses sigam as fases: pré-análise, exploração do material, tratamento dos resultados obtidos e interpretação. Essas fases foram realizadas durante o tratamento dos dados usados na presente pesquisa.

${ }^{5}$ Frigotto (2010), explica que essa primeira concepção, que reúne visões metafísicas diversas, parte de uma compreensão organicista e fisicista da realidade social, das ideias e do pensamento. De tal modo que, mesmo com diferenças significativas de complexidade e alcance, nela incluem-se as abordagens empiristas, positivistas, idealistas, ecléticas e estruturalistas. Já a segunda perspectiva - materialista histórica - funda-se na concepção de que o pensamento e as ideias refletem o plano da organização nervosa superior, as realidades e leis dos processos que se passam no mundo exterior, os quais não dependem do pensamento, e sim, têm suas leis específicas únicas reais, de modo que só compete à reflexão racional apoderar-se das determinações existentes entre as próprias coisas e dar-lhes expressões abstratas, universalizadas, que correspondem ao que se chamará então de "proposições".

6 Segundo Frigotto (2004, p. 2), os jovens pobres sentem-se infelizes por não poderem usufruir as promessas do consumismo; e os filhos da burguesia, por serem levados a um estado de permanente insatisfação com o que consomem. Tomando-se a questão do futuro de jovens filhos de pais com altos salários - gerentes, executivos de grandes empresas (funcionários do capital) -, no contexto de crise do sistema capitalista, encontram-se problemas que, embora de outra natureza em relação aos jovens de classe trabalhadora, os tornam "infelizes".

${ }^{7}$ Para efeito de preservação de face pública dos informantes, nesta pesquisa serão reveladas apenas as iniciais de seus nomes.

8 Rede utilizada pelos pecadores em Cametá-PA para a captura do pescado.

${ }^{9}$ A comunidade a que se faz referência aqui é uma organização ligada à igreja católica e presente nas localidades distantes (as ilhas), onde se localizam as paróquias e arquidioceses cristãs. Assumem o papel de organizar, coordenar e conduzir os trabalhos da igreja católica naqueles locais.

10 Embora o termo Colônia possa suscitar a imagem de um coletivo de pescadores vivendo da pesca à margem de um rio, a Colônia de Pescadores Artesanais Z-16 se constitui na entidade representativa de classe desses sujeitos, reunindo 15.000 associados de diferentes comunidades do município cametaense. Sua fundação data de 1923. Segundo Moraes (2002), a letra Z refere-se à Zona de Pesca e o número 16 indica ser esta Colônia a décima sexta criada no Estado do Pará. Para Costa (2006, p. 153), a Colônia Z-16 se constitui em organização política importante para o alcance dos interesses dos trabalhadores na região em que se encontra o município de Cametá. Rodrigues (2012a) também observou a força política do campesinato regional diante dos setores oligárquicos tradicionais. 


\section{Referências}

ARAUJO, Ronaldo Marcus de Lima; ALVES, João Paulo da Conceição. Juventude, trabalho e educação: questões de diversidade e classe das juventudes na Amazônia. In: SEMINÁRIO LUSO-BRASILEIRO EDUCAÇÃO, TRABALHO E MOVIMENTOS SOCIAIS, 6, 2013, Lisboa. Atas [...] Lisboa: Universidade de Lisboa, 2013. p. 246- 258.

BOGO, Ademar. Identidade e luta de classe. 2. ed. São Paulo: Expressão Popular, 2010.

COSTA, Gilson da Silva. Desenvolvimento rural sustentável com base no paradigma da agroecologia. Belém: UFPA/NAEA, 2006.

DAYRELL, Juarez; GOMES, Nilma Lino. A juventude no Brasil. Serviço Social da Indústria (SESI), [S. I.], n. 30, p. 25-39, 1999. Disponível em: http://www.cmjbh.com.br/ arq_Artigos/SESI\%20JUVENTUDE\%20NO\%20BRASIL.pdf. Acesso em: 9 nov. 2014.

FRANCO, Maria Laura P. B. Análise de conteúdo. Brasília, DF: Liber Livro, 2007.

FRIGOTTO, Gaudêncio. Juventude, trabalho e educação: o presente e o futuro interditados ou em suspenso. In: TIRIBA, Lia; CIAVATTA, Maria (Org.). Trabalho e educação de jovens e adultos. Brasília, DF: Liber Livro; Niterói: EdUFF, 2011.

FRIGOTTO, Gaudêncio. A produtividade da escola improdutiva: um (re)exame das relações entre educação e estrutura econômico-social e capitalista. 9. ed. São Paulo: Cortez: Autores Associados, 2010.

FRIGOTTO, Gaudêncio. Juventude, trabalho e educação no Brasil: perplexidades, desafios e perspectivas. In: NOVAES, R.; VANNUCHI, P. (Org.). Juventude e sociedade: trabalho, educação, cultura e participação. São Paulo: Fundação Perseu Abramo; Porto Alegre: Instituto Cidadania, 2004. p. 180-216.

HOBSBAWM, Eric. 0 novo século. São Paulo: Companhia das Letras, 2000.

IBGE. Contagem da população 2007. Rio de Janeiro: IBGE, 2008. Disponível em: http://www.ibge.gov.br/home/estatistica/populacao/contagem2007/default.shtm. Acesso em: 25 mar. 2010.

JUVENTUDE com vida provisória e em suspenso. Direção de Lara Frigotto. Coordenação de Gaudêncio Frigotto. Rio de Janeiro: Arissas Multimídias, 2009. 1 DVD (50 min), NTSC, son., color.

KOSIK, Karel. Dialética do concreto. 7. ed. São Paulo: Paz e Terra, 2002. 
MARX, Karl. O capital: crítica da economia política. Rio de Janeiro: Civilização Brasileira, 2008.

MINAYO, Maria Cecília de Souza. O desafio da pesquisa social. In: MINAYO, Maria Cecília de Souza (Org.). Pesquisa social: teoria, método e criatividade. Petrópolis: Vozes, 2012.

MORAES, Sérgio Cardoso de. De homens e peixes: a metamorfose da vida na água. 2002. Dissertação (Mestrado em Educação) - Universidade Federal do Rio Grande do Norte, Natal, 2002.

RODRIGUES, Doriedson do Socorro. Saberes do trabalho da pesca e identidade de juventude do município de Cametá: Nordeste da Amazônia paraense. Cametá, 2012a. Projeto de pesquisa aprovado no Conselho Nacional de Desenvolvimento Científico e Tecnológico-CNPQ.

RODRIGUES, Doriedson do Socorro. Saberes sociais e luta de classes: um estudo a partir da Colônia de Pescadores Artesanais Z-16: Cametá/Pará. Belém: [s. n.], 2012b.

RODRIGUES, Doriedson do Socorro; SILVA, Gilmar Pereira da. Saberes do trabalho da pesca de jovens ribeirinhos no Município de Cametá-Pará-Brasil: questões de Identidade e formação do trabalhado. In: ENCONTRO DE PESQUISA EDUCACIONAL DO NORTE NORDESTE, 22., 2014, Natal. Anais [...]. Natal:

Universidade Federal do Rio Grande do Norte/Centro de Educação/Programa de Pós-graduação em Educação, 2014.

SILVA, Gilmar Pereira da. Políticas de formação, currículo e trabalho para a juventude do campo na Amazônia: construindo indicadores de qualidade para o ensino médio do campo, na microrregião de Cametá/Estado do Pará. Cametá, 2013. Projeto de pesquisa do Conselho Nacional de Desenvolvimento Científico e Tecnológico-CNPQ.

SILVA, Jamerson Antônio de Almeida da. As especificidades das políticas de qualificação profissional para a juventude. In: OLIVEIRA, Ramon de (Org.). Jovens, ensino médio e educação profissional: políticas públicas em debate. Campinas: Papirus, 2012.

THIOLLENT, Michel. Crítica metodológica, investigação social e enquete operária. São Paulo: Polis, 1985.

TRIVIÑOS, A. N. S. Introdução à pesquisa em Ciências Sociais: a pesquisa qualitativa em educação. São Paulo: Atlas, 1987. 